\title{
LEOPARD Syndrome
}

National Cancer Institute

\section{Source}

National Cancer Institute. LEOPARD Syndrome. NCI Thesaurus. Code C84820.

A genetic syndrome caused by mutations in the PTPN11 and RAF1 genes. It is characterized by the following abnormalities: multiple lentigines, electrocardiographic conduction abnormalities, ocular hypertelorism, pulmonary stenosis, abnormalities in genitalia, growth retardation, and deafness. 